\title{
Occult tuberculous postpneumonectomy space empyema four years after lung resection
}

\author{
Ph. Rogiers, J. Verschakelen', D. Knockaert and S. Vanneste \\ Division of Internal Medicine and ${ }^{1}$ Division of Radiology, University Hospitals Catholic University of \\ Leuven, Belgium
}

\begin{abstract}
Summary: We describe a patient in whom a tuberculous postpneumonectomy empyema developed 4 years after resection for lung cancer. The clinical presentation was dominated by non-specific constitutional symptoms, without any chest complaints. A computed tomographic scan of the chest suggested inflammation in the postpneumonectomy space. Ultimately Mycobacterium tuberculosis was cultured from material aspirated by needle thoracocentesis.

To our knowledge this is the first report of a tuberculous postpneumonectomy empyema complicating resection for cancer.
\end{abstract}

\section{Introduction}

Empyema thoracis is an uncommon, but serious complication of lung resection caused by both aerobe and anaerobe bacteria. ${ }^{1}$ The clinical picture varies widely, from an obvious inflammatory condition with chest pain, dyspnoea and cough ${ }^{2-4}$ to a total absence of symptoms. ${ }^{5}$ The paucity of specific complaints can lead to a serious delay in diagnosis, particularly when the infection appears a long time after lung resection. ${ }^{5}$

We present a case of late-onset postpneumonectomy empyema caused by Mycobacterium tuberculosis, to our knowledge, a previously unreported complication of resection for cancer.

\section{Case report}

A 67 year old ex-coal mine worker underwent a left pneumonectomy for lung cancer in 1985 . In July 1989 , he was admitted to another hospital because of fever, without further specific complaints. Physical examination revealed no abnormalities apart from the signs of pneumonectomy. Abnormal liver function tests and gall stones, identified by ultrasonography, lead to a diagnosis of cholangitis. Treatment with broad spectrum antibiotics was started, with partial remission of the symptoms.

Correspondence: S. Vanneste, M.D., University Hospital Gasthuisberg, Department of Internal Medicine, Herestraat 49, 3000 Leuven, Belgium

Accepted: 18 February 1991
On admission to our institute in November 1989 he had no specific complaints except for anorexig and a loss of weight of $14 \mathrm{~kg}$. The clinical examina tion was entirely normal, except for diminishees breath sounds over the left hemithorax: Laboratory screening disclosed an erythrocyte sedimentation rate of $130 \mathrm{~mm} /$ hour, haemoglobin value of $11.1 \mathrm{~g} / \mathrm{dl}$, a white blood cell count of $10.6 \times 10^{9} / 1$ with a normal differential count. Apart from a minimally elevated alkaline phosphatase value, liver function tests were normal. A chest $\mathrm{X}$-ray showed an opaque left hemithorax, with shift of the mediastinum to the left, compensatory hyperinflation and apical pleural thickening of the right lung similar to a film 4 years earlier.

Bronchoscopy, echocardiography, ultrasound examination and computed tomography of the abdomen did not reveal any abnormality. A computed tomography of the thorax showed a non-homogeneous postpneumonectomy space, compartmentalized, with an uneven thickened wall, extending to the subcutaneous tissues ventrally, in addition to numerous calcified mediastinal lymph nodes and an irregular calcified coin lesion in the right upper lungfield (Figure 1).

A thoracocentesis of the left hemithorax yielded thick, yellow odourless pus. Ziehl-Nielsen staining revealed abundant acid-fast bacilli, and subsequent Löwenstein cultures grew Mycobacterium tuberculosis. Gram stains were negative and cultures both for aerobes and anaerobes remained sterile. Triple antituberculous therapy with isoniazid, ethambutol and rifampicin was started, in addition 


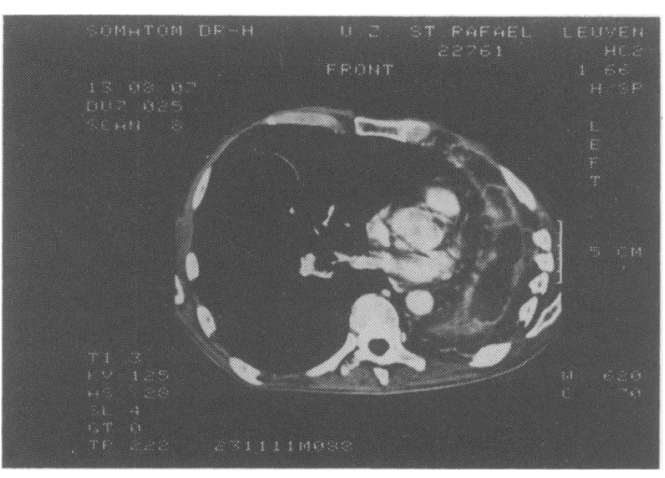

Figure 1 Computed tomography of the chest. The left sided postpneumonectomy space is compartmentalized, with an irregular, unevenly thickened wall. Anteriorly, its content bulges into the subcutaneous tissue.

to weekly thoracocentesis with intrapleural instillation of isoniazid $250 \mathrm{mg}$ and rifampicin $600 \mathrm{mg}$ for 8 weeks. The clinical condition and the signs of inflammation improved steadily. However, 4 months later, open window thoracostomy was performed because of cutaneous break-through.

\section{Discussion}

Tuberculosis in a postpneumonectomy cavity is a very uncommon finding where a pneumonectomy was performed because of neoplasia, and, to our knowledge, this is the first reported case. Empyemas after lung resection for cancer usually are due to Staphylococcus aureus, Streptococcus $s p$., Gram-negative or anaerobic organisms. ${ }^{2}$ Tuberculous superinfection of the postpneumonectomy space probably represents a reactivation from a dormant pleural focus as suggested by the presence of calcified lesions in our case.

Empyema thoracis remains a serious clinical problem, heralding prolonged morbidity and causing significant mortality, especially when involving a postpneumonectomy space. Recent series of empyema give no details of the picture of tuberculous empyema. ${ }^{1-3}$ Classic signs of pyothorax include the development of fever, dyspnoea, chest pain and cough, ${ }^{2-4}$ yet the clinical presentation can be insidious with no signs pointing to the thoracic cavity. Anorexia, weight loss and lassitude can predominate the picture, suggesting tumour recurrence rather than surinfection when a previous resection was performed for neoplasia. ${ }^{1,5,6}$ Grant found that the diagnosis of empyema was recognized only at autopsy in up to $10 \%$ of cases. ${ }^{2}$ Patients can even be completely asymptomatic, the diagnosis being suggested only on radiographic grounds. ${ }^{5}$

Signs on plain film radiography include a decline or reappearance of an air fluid level (bronchopleural or pleuro-oesophageal fistula with or without local tumour recurrence) or shift of the mediastinum towards the normal side. ${ }^{2}$ Computed tomographic abnormalities contributing to the diagnosis of postpneumonectomy empyema are a thickening or irregularity of the cavity wall with a convex medial edge. ${ }^{7}$ Ultimate diagnosis is established by thoracocentesis.

In clinical practice, the postpneumonectomy space sometimes is thought, erroneously, to be completely obliterated by fibrous tissue, and unlikely to get infected. However, this cavity can still contain fluid years after the resection. ${ }^{8}$ Such an isolated pocket of fluid is an ideal culture medium for micro-organisms. Although most postoperative empyemas develop within the first weeks after pneumonectomy, ${ }^{9}$ occasionally intervals of 10 years, ${ }^{10} 13$ years ${ }^{5}$ or 26 years $^{6}$ between the resection and the diagnosis of empyema have been described.

The paucity of specific complaints and the rarity of the predisposition of the postpneumonectomy space to infections frequently lead to a serious delay in diagnosis as revealed by our experience. This allows the empyema to break through the skin (empyema necessitatis) in up to $60 \%$ of the patients. ${ }^{5,6}$

Repeated thoracocentesis can occasionally be successful but the value of repeated intrapleural instillation of antimicrobials, performed to circumvent the diminished penetration in a chronic infectious focus, has not been studied. ${ }^{4}$ The initial response in our patient was clinically successful but the eventual evolution highlights the importance of surgical drainage, either closed or open. ${ }^{2,4}$

\section{References}

1. Le Roux, B.T., Mohlala, M.L., Odell, J.A. \& Whitton, I.D. Suppurative diseases of the lung and pleural space. Part I: Empyema thoracis and lung abscess. Curr Probl Surg 1986, 23: $1-89$.

2. Grant, D.R. \& Finley, R.J. Empyema: analysis of treatment techniques. Can J Surg 1985, 28: 449-451.

3. Lemmer, J.H., Botham, M.J. \& Orringer, M.B. Modern management of adult thoracic empyema. $J$ Thorac Cardiovasc Surg 1985, 90: 849-855.

4. Weese, W.C., Shindler, E.R., Smith, I.M. \& Rabinovich, S. Empyema of the thorax then and now. Arch Intern Med 1973, 131: $516-520$.

5. Kerr, W.F. Late-onset postpneumonectomy empyema. Thorax 1977, 32: 149-154.

6. Stafford, E.G. \& Clacett, O.T. Postpneumonectomy empyema. Neomycin instillation and definitive closure. $J$ Thorac Cardiovasc Surg 1972, 63: 771-775. 
7. Boyer, B., Le Vot, J., Solacroup, J.C. et al. Aspects radiologiques des pneumonectomies. Ann Radiol 1989, 32: 201-207.

8. Biondetti, P.R., Fiore, D., Sartori, F. et al. Evaluation of the postpneumonectomy space by computed tomography. $J$ Comput Assist Tomogr 1982, 6: 238-242.
9. Eerola, S., Virkkula, L. \& Varstela, E. Treatment of postpneumonectomy empyema and associated bronchopleural fistula. Scand J Thorac Cardiovasc Surg 1988, 22: 235-239. 10. Model, D. Occult empyema presenting ten years after pneumonectomy. Lancet 1983, i: 192-193. 